\title{
A PROSPECTIVE STUDY OF LYMPHATIC FILARIASIS IN AN ENDEMIC VILLAGE OF KAPILBASTU DISTRICT, NEPAL
}

\author{
R. Gupta and J. Lamichhane* \\ Associate Professor \\ Central Department of Zoology \\ Tribhuvan University, Kirtipur, Kathmandu \\ *Ex-student \\ Central Department of Zoology \\ Tribhuvan University, Kirtipur, Kathmandu
}

\begin{abstract}
Lymphatic filariasis is a major public health problem in Nepal. A prospective study was conducted in Maharajganj VDC, Kapilbastu district, Nepal with the objective to analyze the epidemiological situation of the disease lymphatic filariasis. A total of 505 blood samples were collected by ear-lobe prick method.

Out of 505 blood samples, 50 samples $(9.90 \%)$ were found to be positive for microfilaria ( $\mathrm{mf}$ ) within age between 3 to 85 years. In the present study the highest endemicity rate was found in the age group 61-70 years and the lowest endemicity rate $6.67 \%$ was found in the age group $\leq 10$ years. Illiteracy, poor sanitation, lack of knowledge about the discase and not taking precaution of filariasis, habit of working in the fields till late night and early in the morning, sleeping outdoor without bed-nets, keeping cattle in the same house where they live were identified as risk factors for the disease.
\end{abstract}

Key words: Prevalence, lymphatic filariasis, microfilaria, crude disease rate.

\section{INTRODUCTION}

Lymphatic filariasis is a major cause of morbidity, primarily lymphoedema of legs and hydrocele. It impedes socioeconomic development in many endemic areas of Nepal. Out of total population of Nepal (23.2 million), approx. $60 \%$ (13.9 million) are estimated at risk of filariasis. Out of three species (Wuchereria bancrofti, Brugia malayi, Brugia timori) of lymphatic filarial parasites, only one species i.e. Wuchereria bancrofti has been reported in Nepal (Thakur 2000)

Outdoor patient, cases of Filariasis in Kapilbastu district of Nepal was 487 in 1995/96, 386 in 2000/01 and 142 in 2004/05 (EDCD 2005). In Nepal, number of lymphatic filarial cases reported in the year 1995/96 was 3100 ; the number was 1797 in 1999/00 and 549 in 2004/05. The objectives of the study were to determine the prevalence of microfilaremia, to study the knowledge, attitude and practices of people towards filariasis and to determine the endemicity rate of lymphatic filariasis.

\section{MATERIALS AND METHODS}

The samples for studying lymphatic filariasis were collected from Maharajganj VDC ward no. 1, Kapilvastu district. A cross-sectional survey design was applied as a research tool in this study. A total of 505 blood samples were collected from the people and the questionnaire of the same population was taken. Human blood samples were drawn out by ear-lobe prick method during night 
time at 10:00 $\mathrm{AM}$ to $2: 30 \mathrm{AM}$, when the people were in relaxed condition in their beds. The collection and examination process of blood films were done by WHO (2005) standard. Microfilariae were observed and identified as Wuchereria bancrofti on the basis of its characteristic features.

\section{RESULTS}

Out of total 505 blood samples examined for the detection of the human microfilarial $(\mathrm{mf})$ infection, 50 blood samples $(9.90 \%)$ showed the presence of microfilaria. Among 269 male blood samples, 30 were $\mathrm{mf}$ positive and out of 236 female blood samples, 20 were $\mathrm{mf}$ positive. Statistically, the difference in prevalence of microfilaria in both the sexes was found to be significant $\left(\chi_{2}=1.01, \mathrm{P}>0.05, \mathrm{df}=3\right)$.

Age-wise distribution of microfilaria ( $\mathrm{mf}$ ): The highest rate of infection was found in $61-70$ years age - group. Out of 15 total samples from this group, 3 were found to be $\mathrm{mf}$ positive. Two $\mathrm{mf}$ positive samples were of males and 1 was of female. Whereas the least rate of infection was found in $\leq 10$ years age group. Out of total 120 samples, 8 were found to be $\mathrm{mf}$ positive in which among the 68 male blood samples, 5 were found to be $\mathrm{mf}$ positive and out of 52 female blood samples, 3 were found $\mathrm{mf}$ positive. Statistically, the difference in the prevalence of microfilaria in different age-groups were found to be significant $(\chi 2=5.40, P>0.05, d f=15)$ (Fig. 1).

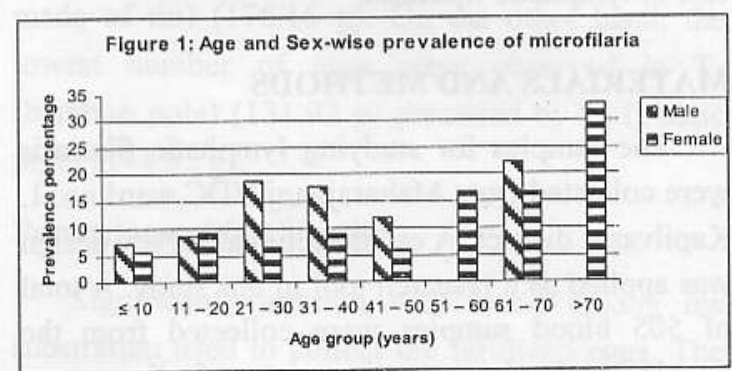

Education-wise distribution of $\mathrm{mf}$ : The highest rate of infection was found in literate (having informal education) population. In this group out of 95 total samples, $14 \mathrm{mf}$ positive cases (14.74\%) were reported. The lowest rate of infection was found in population with secondary and higher educational status. Here out of 100 total samples, 8 showed $\mathrm{mf}$ positive cases. Statistically, the difference in the distribution of microfilaria in different educational status was found to be significant $\left(\chi^{2}=3.21, \mathrm{P}>0.05, \mathrm{df}=7\right)$ (Fig. 2).

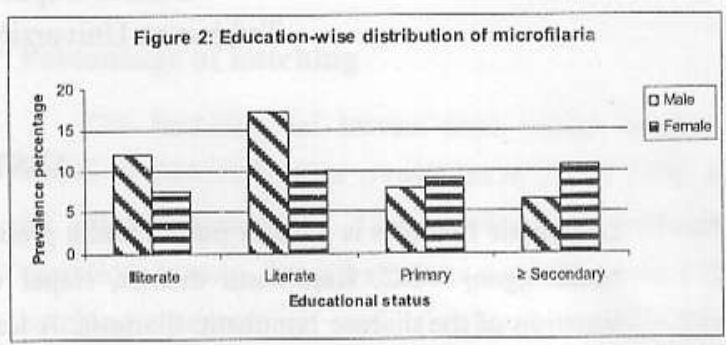

Occupation-wise distribution of mf: Out of 145 farmers, $15.86 \% \mathrm{mf}$ positive cases were recorded. The highest percentage $(16.67 \%)$ of filariasis positive case was recorded among labor whose total studied population was 6. Out of 151 students, $7.28 \% \mathrm{mf}$ positive cases were recorded. Teachers and others were found to be not infected by microfilaria. Statistically, the difference in the distribution of microfilaria in different occupation was found to be significant $(\chi 2=11.88, \mathrm{P}>0.05$, $\mathrm{df}=17$ ) (Fig. 3).

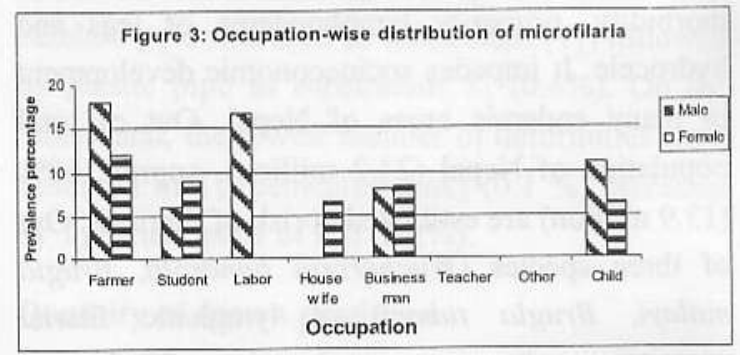

Knowledge-wise distribution of mf: Only a few people had the knowledge of lymphatic filariasis. $81.39 \%$ people were unaware of filariasis. They did not have knowledge about the disease, its vector and transmission. Out of 411 people who had no knowledge of lymphatic filariasis, 39 were 
mf positive, whereas out of 94 people who had knowledge of lymphatic filariasis, 11 were $\mathrm{mf}$ positive (Table 1).

Distribution of $\mathrm{Lf}$ in relation to the use of mosquito-nets: Out of total 505 studied population, 285 were found to use bed - nets while sleeping, among them 35 were $\mathrm{mf}$ positive. Whereas, out of 220 people who were not using bed - nets, 15 were $\mathrm{mf}$ positive. Mf positive was found more in net using people (Table 2).

Clinically manifested persons in the study population: A total of 505 persons were examined. Ten persons had signs and symptoms of lymphatic filariasis. Among them 4 were males and 6 were females. Hence overall crude disease rate was recorded to be 10 , male $0.79 \%$ and female $1.19 \%$. The highest crude disease rate was recorded in 41-50 years age-group. Out of 42 people from this group, 4 had signs and symptoms (Table 3) of lymphatic filariasis. Whereas the least crude disease rate was found in 21-30 years agegroup. Out of total 89 people, 1 had signs and symptoms of lymphatic filariasis. No sign and symptoms of lymphatic filariasis was recorded in the people of the age-groups $\leq 10$ years, $11-20$ years and $>70$ years (Table 3 ).

Endemicity rate (ER): The overall endemicity rate of lymphatic filariasis in Maharajganj VDC of Kapilbastu district in 505 total studied population was found to be $11.68 \%$. In this microfilariaemia (mf) was 49, crude disease rate (CDR) was 9 $(1.78 \%)$ and $\mathrm{MF}+\mathrm{CDR}$ was $1(0.20 \%)$ (Fig. 4).

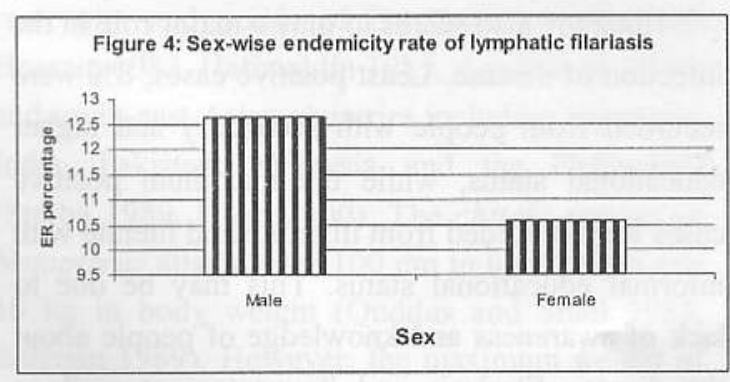

ECOPRINT VOL 13, 2006
Age and sex-wise ER: The overall study showed that the highest endemicity rate was found in the age group $61-70$ years $(26.67 \%$ of 4 samples), among which endemicity rate of males was found to be $33.33 \%$ of 3 samples and endemicity rate of female was found to be $16.67 \%$. The least endemicity rate was found in the age group $\leq 10$ years $(6.67 \%$ samples), among which endemicity rate of males was found to be $7.35 \%$ samples and endemicity rate of females was found to be $5.77 \%$ samples (Fig. 5).

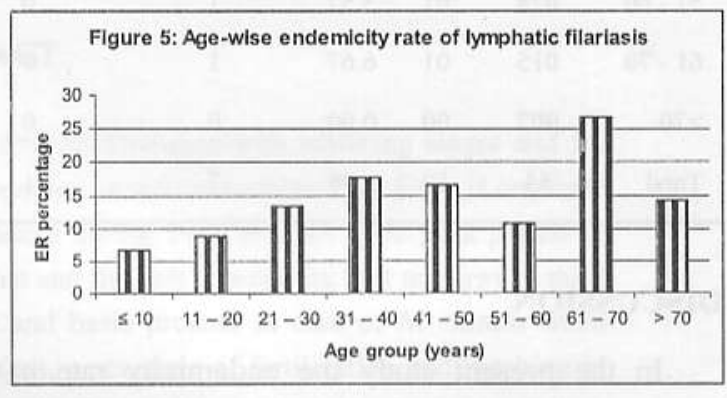

*Literate $=$ adult education (having informal education).

Table 1. Distribution of microfilaria in relation to knowledge of LF.

\begin{tabular}{lcccc}
\hline \multirow{2}{*}{$\begin{array}{l}\text { Knowledge about } \\
\text { filariasis }\end{array}$} & \multicolumn{2}{c}{ People } & \multicolumn{2}{c}{ Mf positive } \\
& No & $\%$ & No & $\%$ \\
\hline Yes & 094 & 18.61 & 11 & 11.70 \\
No & 411 & 81.39 & 39 & 09.49 \\
Total & 505 & 100 & 50 & 9.90 \\
\hline
\end{tabular}

Table 2. Distribution of $\mathbf{L f}$ in relation to the use of mosquito-nets.

\begin{tabular}{lcccc}
\hline \multirow{2}{*}{ Use of } & \multicolumn{2}{c}{ People } & \multicolumn{2}{c}{ Mf positive } \\
mosquito nets & No & $\%$ & No & $\%$ \\
\hline Yes & 285 & 56.44 & 35 & 12.28 \\
No & 220 & 43.56 & 15 & 06.82 \\
Total & 505 & 100 & 50 & 9.90 \\
\hline
\end{tabular}


Table 3. Clinically manifested persons in the study population

\begin{tabular}{|c|c|c|c|c|c|c|c|c|c|c|c|}
\hline \multirow[t]{2}{*}{$\begin{array}{l}\text { Age } \\
\text { group } \\
\text { (year) }\end{array}$} & \multirow[t]{2}{*}{$\begin{array}{l}\text { Total } \\
\text { sample }\end{array}$} & \multicolumn{2}{|c|}{$\begin{array}{l}\text { Total } \\
\text { cases }\end{array}$} & \multirow[t]{2}{*}{$\begin{array}{c}\text { Swollen } \\
\text { limbs }\end{array}$} & \multirow[t]{2}{*}{$\begin{array}{l}\text { otal } \\
\text { Swollen } \\
\text { nerves }\end{array}$} & \multirow[t]{2}{*}{ Elephantiasis } & \multirow[t]{2}{*}{ Chyluria } & \multicolumn{2}{|c|}{$\begin{array}{l}\text { Male } \\
\text { Total } \\
\text { cases }\end{array}$} & \multicolumn{2}{|c|}{$\begin{array}{c}\text { Female } \\
\text { Total } \\
\text { cases }\end{array}$} \\
\hline & & No. & $\%$ & & & & & No & $\%$ & No & $\%$ \\
\hline$\leq 10$ & 120 & 00 & 0.00 & 0 & 0 & 0 & 0 & 0 & 000 & 0 & 000 \\
\hline $11-20$ & 136 & 00 & 0.00 & 0 & 0 & 0 & 0 & 0 & 000 & 0 & 000 \\
\hline $21-30$ & 089 & 01 & 1.12 & 0 & 1 & 0 & 0 & 1 & 100 & 0 & 000 \\
\hline $31-40$ & 068 & 03 & 4.41 & 2 & 0 & 0 & 1 & 0 & 000 & 3 & 100 \\
\hline $41-50$ & 042 & 04 & 9.52 & 3 & 0 & 1 & 0 & 1 & 025 & 3 & 075 \\
\hline $51-60$ & 028 & 01 & 3.57 & 1 & 0 & 0 & 0 & 1 & 100 & 0 & 000 \\
\hline $61-70$ & 015 & 01 & 6.67 & 1 & 0 & 0 & 0 & 1 & 100 & 0 & 000 \\
\hline$>70$ & 007 & 00 & 0.00 & 0 & 0 & 0 & 0 & 0 & 000 & 0 & 000 \\
\hline Total & 55 & 10 & 1.98 & 7 & 1 & 1 & 1 & 4 & 0.79 & 6 & 1.19 \\
\hline
\end{tabular}

\section{DISCUSSION}

In the present study the endemicity rate of lymphatic filariasis was recorded $11.68 \%$. Prevalence of filariasis was higher in males than in females. This may be because males are mostly involved in field work, where chances of mosquito biting are more. The favourable breeding season of the mosquito is the summer season. During this period males usually sleep outdoor and hence are more exposed to the mosquito biting. While females mostly sleep indoor with their children. They use mosquito nets to prevent the children from mosquito biting and hence are less exposed to mosquitoes.

In the present study highest $20 \%$ prevalence rate of microfilaria was recorded in the age group 61-70 years and the lowest prevalence rate $6.66 \%$ was recorded in the age group $\leq 10$ years. The highest prevalence rate of microfilariae may be due to maximum exposure towards outer environment, lack of awareness and knowledge of filariasis, carelessness towards using mosquito-nets, etc. Mf positive was found more in mosquito-net using people. This may be because in hot days, people prefer to work in the fields till late night and early in the morning, which are peak biting hours of mosquitoes, so the chances of mosquito biting is more.

The children and students of age group $\leq 10$ years are at higher risk of infection with Lf. This may be due to low socioeconomic status of their parents. They go to the field and sleep outdoor without bed-nets, hence are exposed to mosquito biting. They do not have knowledge about the disease and its protective measures. The present study showed $1.98 \%$ crude disease rate. The highest crude disease rate was recorded in the age group 41-50 years and the lowest crude disease rate was recorded in the age group 21-30 years.

Illiteracy also seems to play a major role in the infection of disease. Least positive cases, $8 \%$ were recorded from people with secondary and higher educational status, while the maximum positive cases were recorded from illiterate and literate with informal educational status. This may be due to lack of awareness and knowledge of people about the disease filariasis and its vectors as well as 
preventive measures. Lymphatic filariasis is a disease of poor environmental condition with low socioeconomic status, low literacy rate and high percentage of illiterate health education status (WHO 1997).

Occupation was also found to be a major factor for prevalence of the disease. Among farmers, $15.38 \%$ positive cases of filariasis were recorded, $7.28 \%$ were recorded among students, and $6.58 \%$ were recorded among housewives. No positive case was recorded among teachers. The farmers keep cattle in the same house where they live. Cattlesheds are one of the most favourable breeding sites for the vector mosquito and hence have more chances of being bitten by mosquitoes. They have habit of working in the field during morning and evening time which is also a suitable time for mosquito biting. Most of the surrounding environment of the house is dirty with dead and decaying organic matters, stagnant water, bushy places, open drainage which are suitable sites for mosquito breeding. Hence people living in that environment have maximum chances of mosquito biting, which increases the disease prevalence. They are illiterate, poor and unaware of the diseases. These are risk factors which increases the disease prevalence. Comparatively teachers and others have a better life and possess healthy life style and have knowledge of the disease, hence no positive case was recorded from these groups.

\section{ACKNOWLEDGEMENTS}

We sincerely thank 'PARASED' (Parasitological Research and SocioEnvironmental Development, Nepal) for involving us in the project which was sponsored by Filariasis Elimination Programme, EDCD, Teku, Kathmandu. We also thank all the local people of the study area for their help and contribution during the field work.

\section{REFERENCES}

Annonymous. 1997a. Lymphatic Filariasis Research for Hope. World Health Organization. CTD/FIL, 4:1-20.

Annonymous. 1997b. Lymphatic Filariasis. TDR Thirteen Programme Report. World Health Organization. 75-85.

Annonymous. 2000. Lymphatic filariasis: Review of Literature and Epidemiological Analysis of the Situation in Nepal, 1945-1999. Epidemiology and Disease Control Division, Department of Health Services, Ministry of Health, HMG-Nepal.

Annonymous. 2005. Monitoring and Epidemiological Assessment of the program to eliminate Lymphatic filariasis at implementation unit level. World Health Organization.

Annonymous. 2005. Review of Literature and Epidemiological Analysis of the Situation in Nepal. Epidemiology and Disease Control Division, Department of Health Services, Ministry of Health, HMG-Nepal.

Arora, D.R. and B. Arora. 2001. Wuchereria bancrofti. Medical Parasitology, $1^{\text {st }}$ Ed., CBS Publishers and Distributors, New Delhi, pp. 173-179.

Chatterjee, K.D. 1980. Filarioidea. Protozoology and Helminthology, $12^{\text {th }}$ Ed., Shree Saraswati Press, Calcutta, 187-198.

Cheesbrough, M. 1998. Examination of blood for microfilariae in lymphatic filariasis and loiasis.

District Laboratory Practice in Tropical Countries, $1^{\text {st }}$ Ed., Cambridge University Press, UK. pp. 280-292.

Cheng, T.C. 1986. Superfamily Filarioidea. General Parasitology, $2^{\text {nd }}$ Ed., Academic Press, California, pp. 550-563. 
Rozendaal, J.A. 1999. Lymphatic Filariasis. Vector control, $1^{\text {st }}$ Ed., WHO, Geneva, pp. 29-33.

Sherchand, J.B., V. Obsomer, G.D. Thakur and M. Hommel. 2002. Mapping of lymphatic filariasis in Nepal. Filaria Journal of $W H O$, www. filaria journal.com/content/2/1/7.

Sherchand, S. 2003. Demonstration of strategy for the elimination of lymphatic filariasis
(Wuchereria bancrofti) in Nepal. Journal of Nepal Health Research Council, Nepal 1(2):25-29.

Thakur, G.D. 2000. Epidemiological situation of lymphatic filariasis in Nepal. Report submitted to Ministry of Health, Vector Borne Disease Research and Training Centre, Hetauda, Nepal. 